\section{The Multifunctional}

\section{Digital Center: A Concept for Developing Countries in the Electronic Age}

\author{
Philip G. Altbach \\ Philip G. Altbach is J. Donald Monan, SJ Professor of Higher Education \\ at Boston College.
}

$\mathrm{H}$ igher education faces multiple problems in the new millennium, and these are especially acute in developing countries, where expansion is taking place at the same time that state financing is declining and the challenges of technology, access, and the maintenance of quality loom ever larger. The idea of The Multifunctional Digital Center (MDC) provides an important solution to some of the problems faced by higher education in developing countries and has lessons for industrialized nations as well.

The idea of the multifunctional digital center is based on a simple concept - the provision in one physical space of access to knowledge. It is part traditional library, part multimedia station, and part link to the Internet and all of the resources of cyberspace. Staffed by professionals skilled both in information technology and retrieval and in pedagogy, MDC serves the needs of people studying in traditional academic institutions, those involved in formal study through distance education, and people simply interested in acquiring knowledge and information.

MDC is hardly a new idea. It links the old concept of the public library, committed to storing and providing knowledge without cost, with the idea of a "university extension" offering educational programs for degrees or for specific training or personal opportunities, either on-campus or at other sites. MDC depends on skilled professionals and innovative uses of new technologies. Such a program requires sponsorship for both funding and ideas.

The multifunctional digital center is based on a simple concept-the provision in one physical space of access to knowledge.

The multifunctional digital center is ideally suited to the realities and the new technologies of the $21^{\text {st }}$ century. It can introduce established educational institutions, such as universities, to new approaches to communication and knowl- edge, and provide access to people with different interests, backgrounds, and needs. Public and private institutions are able to enter into cooperative arrangements. MDC can also provide a forum for people who are concerned with education, and in this way it can be an important contributor to the maintenance of a civil society. In short, this approach combines the technological access of the $21^{\text {st }}$ century with the human interaction necessary in all eras.

\section{New Realities}

Everywhere facing new challenges, traditional academic institutions are no longer able to cope with demands for access, training, and research in a growing number of fields. The problems are especially acute in developing countries.

- Worldwide, the demand for higher education continues to grow, but the demand is greatest in developing nations, where in 2000, half the students in postsecondary education are located.

- Providing sufficient funds for higher education is especially problematical in developing countries. There is resistance everywhere to the ever-expanding public expenditures for higher education. In developing countries, enrollment pressures add to the general fiscal difficulties. - Privatization is a key characteristic of higher education in developing countries. Private institutions, sometimes profit-making, are taking hold in higher education. In many developing countries, the private sector is the fastest growing part of the higher education system.

- The knowledge revolution is dramatically altering the landscape of higher education. Knowledge is expanding rapidly, and the means of storing and distributing information is being transformed by the Internet and computer-based technologies.

- Developing countries control neither the sources nor the means of delivery of the knowledge, and consequently they are in danger of being overwhelmed by the new technologies. These countries may benefit from the knowledge revolution, but, at present these countries are falling further behind. Individual academic institutions in developing countries can rarely make the investments needed to access the new technologies.

\section{The Advantages for Developing Countries}

The MDC concept can have key advantages for developing countries. Without question, the needs are greatest in low percapita income nations of Africa, Asia, and Latin America-many of which lack adequate higher education institutions and all of which lag far behind in Internet access and other elements of knowledge-based economy.

- In countries with poorly developed basic infrastructures, including telephone system and electricity provision, MDC can set up a central facility able to provide basic access such as auxiliary generators, satellite-based Internet 
access (to circumvent unreliable telephone systems and speed up data transmission), suitable computers, and adequate maintenance of facilities.

- MDC can promote cooperation among public and private agencies to provide support and funding. As a public facility, MDC should generally be available without cost or at a very low cost to individuals and organizations, but it can also be supported by many agencies. Academic institutions, both public and private, government agencies, local and regional organizations, and private sector firms may all contribute. The MDC would provide technology firms with an opportunity to expose the public to the advantages of knowledge products of all kinds.

- Such projects can be a conduit for support from NGOs, foreign assistance agencies, the World Bank, and similar organizations. Donor groups appreciate variety of importance services offered and the ease of monitoring for effectiveness and fiscal accountability.

- MDCs can be strategically placed throughout a country to allow access to a broad segment of the population, minimizing regional disparities and political conflicts.

- The multifunctional digital center can be used as an extension agency by agencies to offer programming and access to Internet and library facilities in areas inadequately served by traditional educational institutions. MDC will be especially useful for the burgeoning open university movement which provides academic degree study through nontraditional methods. They can serve as regional centers, resource bases, and meeting places for seminars for the offerings of the open universities.

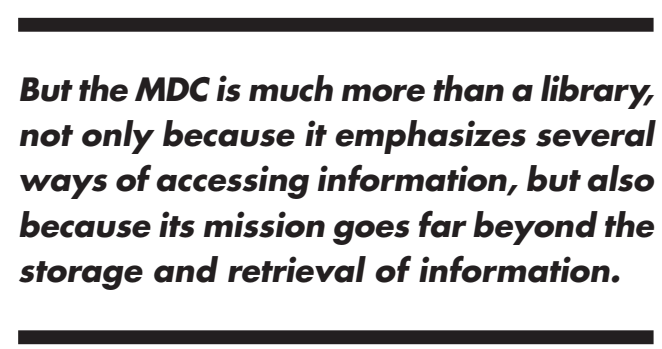

\section{The Shape of the Commons}

What will a multifunctional digital center look like? Of course, there will be variations among them, but there are central elements. It is not a virtual entity although one its main purposes will be to provide access to the new technologies of communication and information retrieval-it is a place where several central knowledge functions are offered. It must be housed in a facility that provides both the needed material and adequate access. The closest analogy may be the public library, a building that provides access to information, largely through books but in some countries now through Internet-based technology, and is staffed by people trained to assist people to effective use the materials available.

But the MDC is much more than a library, not only because it emphasizes several ways of accessing information, but also because its mission goes far beyond the storage and retrieval of information. It should be noted that adequate public library systems are in any case rare in developing countries, and in general, are unfortunately not seen central elements for the information society.

The multifunctional digital center starts with a building that houses all of the elements of the modern information society. Traditional books and journals as well as the newer technologies for knowledge retrieval and dissemination are a central part of the equation. The new technologies will, of course, play a prominent role in MDC, and will no doubt receive the bulk of attention, energy, and funding. Among the elements of the revolution are the following:

- The Internet is the most powerful, and in many ways the most controversial part. It is the key element of globalization and is the means of bringing the world's storehouse of knowledge to the most remote locations. However, the Internet is dominated by a few industrialized countries, and it is increasingly commercialized. The major world languages, and especially English, dominate the Internet. The structure, organization, and financing of the Internet has, so far, largely ignored the needs of developing countries. It is, of course, necessary for developing countries to have access to the Internet, but attention also needs to be given to how this powerful new mechanism can be most effectively used by them.

- Electronic mail and related communications arrangements are an essential tool to bring Third World users in touch with each other as well as with colleagues in the rest of the world. MDC will provide a central node of communications for individuals and groups.

- "The electronic classroom" or seminar is in the process of development, and this tool will be a central contribution of MDC. The ability to bring groups together electronically, through video conferencing and other means, helps to overcome isolation. The multifunctional digital center will have facilities for group communications that can be used by educational institutions and others.

- Older "new technologies" such as CD-ROM, DVD and others will be a part of the services provided by the MDC. In developing countries, it is rare that academic institutions or other organizations have ready access to these knowledge products.

A central feature of the multifunctional digital center is a staff that provides expertise in the new technologies, as well as in traditional librarianship. Many assume that the new technologies are user-friendly, and can easily be accessed-and maintained-by clients. This is far from the truth, especially in developing countries, where there is no tradi- 
tion of expertise or widespread individual access to computers, the Internet or the other tools of communication. Technological librarians are a central part of MDC concept and must play a key role. It is not enough to provide the "hardware" of technology - the human "software" of expertise must be part of the equation. An added element is the maintenance of equipment, decision-making with regard to the purchase of new machinery, software, other knowledge products is central, and often one of the weaknesses in developing countries. MDC will need to have excellent staff and access to spare parts as well as to "upgrades" in equipment if it is to be effective and sustainable.

\section{A central feature of the multifunctional digital center is a staff that provides expertise in the new technologies, as well as in traditional librarianship.}

The location of MDC is an issue of considerable importance, and perhaps controversy. If limited to the capitol or major academic centers, the underlying concept will be lost. MDC must be available to users outside metropolitan centers in developing countries. It will not be possible to establish one in rural areas or villages, but care must be taken to ensure that the MDC will not simply be another initiative that further strengthens the domination of the urban centers.

\section{Funding the multifunctional digital center}

While the MDC will be much less costly than a university or even a specialized educational institution, it will require investment, both for initial development and long-term operation. Without adequate funding, MDC cannot fulfill its promise, especially since information technology rapidly changes and it is important to keep up with new products and services, without appropriate funding. One of the advantages of the MDC concept is that it can receive financial support from many sources. The multifunctional digital center should be a non-profit entity separated from direct government control. This not only permits autonomy but also makes it easier for nongovernmental organizations to provide support.

Because MDC is a public service, it must have basic support from governmental sources. Other providers can easily participate in support MDC. For example, academic institutions that use MDC services can provide support. Private enterprise can also provide support. Computer and software firms, where they exist, are a natural source of support, especially since the users of MDC will be using computer products and familiarizing themselves with the poten- tial of computers and of information technology. Supporting MDC is an effective way for a firm to show its support for education and the public good through a highly visible agency.

The multifunctional digital center lends itself very well to support from external donors and such multilateral agencies as the World Bank. MDC combines a physical facility with support for human resources. It can potentially contribute to education at all levels, and especially at the postsecondary level. It directly assists the development of civil society through providing information to people and organizations and serving as a hub for communications. Care must be taken to ensure that the basic decisions concerning choice of equipment and related issues remains with local policymakers, since external donors often seek to tie aid to particular products, and in the area of information technology, problems of computability may arise. Because The multifunctional digital center serves a variety of purposes and because it is so clearly a contribution to education and socio-economic development, it will appeal to donor agencies. While it is always difficult to manage a multiplicity of funding sources, MDC can benefit from the fact that it serves many purposes.

\section{The location of MDC is an issue of con- siderable importance, and perhaps con- troversy.}

\section{Conclusion}

The multifunctional digital center has the potential of linking the technologies of the $21^{\text {st }}$ century with the idea of community of an earlier era in a cost-effective way. It can provide universities that cannot afford sophisticated computer systems with the access that they need to the world of research and communication. It can link public and private institutions. It can attract financial supporters at home and abroad. Perhaps most important. The multifunctional digital center is an idea can bring information, communication, and knowledge to people in developing countries.

Author's Note: I am indebted to Kamal Ahmad for articulating the idea of the Learning Commons initially, related to the MDC, and to the staff of the Task Force on Higher Education and Society for discussions concerning it.

\section{Internet Resource}

For more information on issues related to international and comparative higher education, visit the Center's website, located at: http://www.bc.edu/cihe/ 